\title{
Integration of the Google Suite for Education in competency based ICT training for Bachelor students: Empirical findings from the IAG-CoRECE project
}

\author{
Ibrahim Sidi Zakari ${ }^{1}$ \\ \{ $\underline{\text { sidizakariibrahim@gmail.com }}{ }^{1}$ isidizakari@ refer.ne ${ }^{1}$ \} \\ Department of Mathematics and Computer Science (Abdou Moumouni University), Office $\mathrm{N}^{\circ} 8$ \\ POBox 10896, Niamey (Niger) ${ }^{1}$.
}

\begin{abstract}
In the knowledge society and a growing number of jobs across many sectors requiring ICT skills, particularly cloud based technology, competency based ICT training is necessary. The Google Suite for Education, as a versatile tool, allows working anywhere, anytime, and on any device; facts that encourage collaboration, creativity, and critical thinking, and let teachers work one-on-one or with the whole class. Moreover, these tools allow instant feedback and track individual progress to improve student performance. From 2015 to 2017, around 400 students on average participated to the IAG-CoRECE project each year including $86 \%$ of Male and $14 \%$ of female. Moreover, the project website seemed to be visited through mobile devices running on Android platform. Students feedbacks are related to gain of productivity and motivation but also challenges they face when uploading documents in the collaborative workspace, accessing to the project online videos or participating to the discussion forum.
\end{abstract}

Keywords: ICT Pedagogy Integration, ICT adoption, Google Suite for Education, Productivity tools, Competency based learning, Knowledge Co-creation, Mobile learning, Intelligent learning system, Youth ICT skills, Sustainable Development Goals.

\section{Introduction}

Competency based learning has been widely investigated in litterature and is currently one of the mostly used in universities including Abdou Moumouni University of Niamey ([1], [2], [3]).

Niger has a National Higher Education and Research Policy (PNESR ${ }^{1}$ ), developed in 2003 and updated in 2012 within the UEMOA/PAES ${ }^{2}$ framework, as well as a Science, Technology and Innovation Policy $\left(\mathrm{POSTINI}^{3}\right.$ ), validated in 2012.

The legal framework includes also the Law of Orientation of the Nigerien Educational System (Law $n^{\circ} 98-12$ of june $\left.1^{\text {st }} 1998\right)^{4}$.

${ }^{1}$ Politique Nationale d'Enseignement Supérieur et de Recherche

${ }^{2}$ Union Economique et Monétaire Ouest Africaine/Programme d'Appui à l'Enseignement Supérieur

${ }^{3}$ Politique des Sciences, Technologie et Innovation du Niger

${ }^{4}$ Loi d'Orientation du Système Educatif Nigérien (http://www.men.ne/RLR/textes/40-0.html): accessed on 30/10/2017. 
Furthermore, competency standards exist worldwide ([4], [5], [6]); but in some cases where national ICT standards for students do not exist, teachers or universities are also facing the challenge to develop and implement local competency-based ICT standards.

Although cloud based technologies positively impact education, some great challenges remain in developing countries [7]. Particularly in terms of raising awarness on its importance, access, the implementation cost, its sustainability in terms of infrastructure and promoting lifelong learning.

The ICT based knowledge co-creation requires also continous adaptation from all of the stakeholders (teachers and students).

Access to the internet and computers for pedagogical purposes, youth ICT skills, mobile phone owning, mobile network coverage (broken down by technology), Fixed Internet broadband subscriptions (broken down by speed) and proportions of individuals using the internet are among the 7 indicators included in the IAEG-SDG ${ }^{5}$ report 2016[8].

ICT adoption by Youth, Development and Education relationshipships have been also investigated in litterature ([9], [10], [11]).

Some authors focused on the impact of innovative teaching and learning [12], or the impact of ICT on student's motivation and success ([13], [14]).

Google Suite (G Suite) for Education offers many advantages including protected environment, academic email addresses, easy sharing and collaboration, scheduling, productivity, money saving for universities, availability across all platform, quick and easy assessment tools, accessibility to cloud storage, online video service, mapping services, and for increasing students motivation to learn as they feel that they are key actors in the process. Moreover, this cloud based technology allows users to benefit from synchrone and asynchrone communication, access to services and ressources anywhere at any time and from any device. Introducing the use of ICT in a course or program enhances the learning of higher education students [13].

Finally, as highlighted in [15], the interaction beetween science and society is very important and ICT represent a key element in this ecosystem.

\section{Background and Methodology}

The IAG-CoRECE ${ }^{6}$ project was initiated in 2015 at Faculty of Sciences and Techniques (Abdou Moumouni University) in order to enhance bachelor students ICT competencies, skills and ethics so that they will be more competitive in the era of knowledge society. Taking into account the technical/infrastructure landscape, electrical energy supply, access to the internet and stakeholders' current ICT readiness; the G Suite for Education ${ }^{7}$ has been identified as the most relevant and feasible solution.

Around 400 students on average are enrolling in this training per year; with background in Mathematics, Computer Science, Geology, Biology, Chemistry, Biochemistry, Physics, Electronic and Electrotechnical and Automatism.

\footnotetext{
${ }^{5}$ Inter-Agency and Expert Group on Sustainable Development Goal Indicators

${ }^{6}$ IAG-CoRECE: Intégration des Applications Google dans la Co-création de Ressources éducatives et l'Evaluation des Compétences des Etudiants.

${ }^{7}$ Previously named Google Apps For Education.
} 
Each year, the syllabus is updated by taking into account the evolution of the university policy, learners needs and exceptations, previous evaluation outcomes, technological evolution and national policy. Furthermore, a control of the prerequisites, the learning objectives are formulated followed by the organization of the contents, the educational activities (teaching and learning activities) as well as the evaluation. Pedagogical alignment is necessary in order to ensure consistency between objectives, activities, content and evaluation. The six competencies (according to the syllabus) are:

Competency 1: To be able to identify the hardware, equipment and software needed to perform a specific learning activity.

Competency 2: To be able to create and use a webmail in academic context

Competency 3: To be able to design documents intended to be printed, saved, stored and shared.

Competency 4: To be able to use an online collaborative workspace

Competency 5: To be able to do documentary research on the Internet

Competency 6: To be able to apply the rules of ethics and intellectual property in the digital era.

Our analysis will use quantitative and qualitative approaches based on data gathered through the project website $^{8}$, collaborative space, discussion forum, online surveys, learners observation and semi structured interview. In terms of pedagogy, we use the G Suite for sharing documents and to engage students in problem solving and project based learning experiences that support social interaction, collaborative knowledge production, innovation and communication.

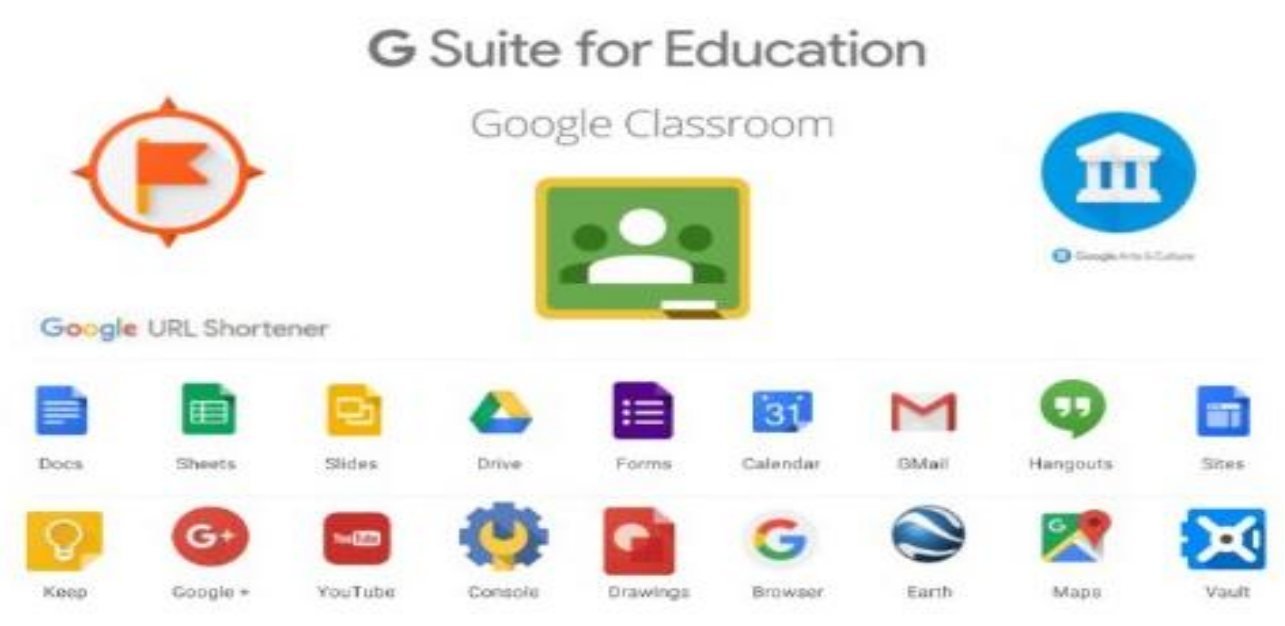

Fig. 1. Google Suite for Education ${ }^{9}$ core Applications used in the IAG-CoRECE Project.

\footnotetext{
${ }^{8}$ https://sites.google.com/site/ticl2fastuam/

${ }^{9}$ Figure from https://cairngormfutures.co.uk/
} 


\section{Evolution of the integration of G Suite for Education in the project}

Table 1. Outputs of the IAG-CoRECE project ${ }^{10}$

\begin{tabular}{|c|c|c|}
\hline 2015 & 2016 & 2017 \\
\hline Syllabus & Syllabus & Syllabus \\
\hline Google site & Google site & Google site \\
\hline Calendar & Calendar & Calendar \\
\hline Templates & Templates & Templates \\
\hline Collaboration tools & Collaboration tools & Collaboration tools \\
\hline Academic e-mails & Academic e-mails & Academic e-mails \\
\hline \multirow[t]{3}{*}{ Forms(monitoring) } & Forms(monitoring) & Forms(monitoring) \\
\hline & Open mapping (homework) & $\begin{array}{l}\text { SDGs awarness } \\
\text { raising (homework) }\end{array}$ \\
\hline & Forms(assessment) & $\begin{array}{l}\text { Forms(assessment+ } \\
\text { automatic correction) }\end{array}$ \\
\hline \multirow{3}{*}{ Learners profil } & Learners profil & Learners profil \\
\hline & Analytics tools & Analytics tools \\
\hline & Learners perception & Learners perception \\
\hline \multirow{7}{*}{ Databases } & Databases & Databases \\
\hline & & $\begin{array}{l}\text { Data disaggregation } \\
\text { by sex }\end{array}$ \\
\hline & QR Codes & QR Codes \\
\hline & & Photos Database \\
\hline & & Discussion forum \\
\hline & & Google Classroom \\
\hline & & YouTube channel \\
\hline
\end{tabular}

As we can see, Table 1. summarized the outputs related to the evolution of the IAG-CoRECE project in terms of outcomes and the integration of the G Suite productivity tools and services (see Figure 1). Year after year, the project integrates new tools and services in order to improve quality of education and to engaging more effectively the learners.

\section{Learners profil $^{11}$}

The learners profil (gender and area of specialization) is presented in Figure 2. This profil highlighted the fact that gender inequality ${ }^{12}$ is still present beetween male $(86,1 \%)$ and female $(13,9 \%)$. Moreover the two most important (in terms of size) groups are biology followed by Geology. Mathematics and Physics are the underrepresented groups. We observed the same repartition in 2015 and 2016. The pie charts were obtained by using Google forms.

\footnotetext{
10 A short video summarizing the project has been selected on October 2017 for the Agence Universitaire de la Francopohie (AUF) Regional Competition on pedagogical innovation entitled « Mon innovation en 120 secondes ». The video is available at https://youtu.be/76EWKi583eA

${ }^{11}$ Based on 2017 cohort which has 337 students.

${ }^{12}$ Physics and EEA groups didn't yet have female students since 2015.
} 


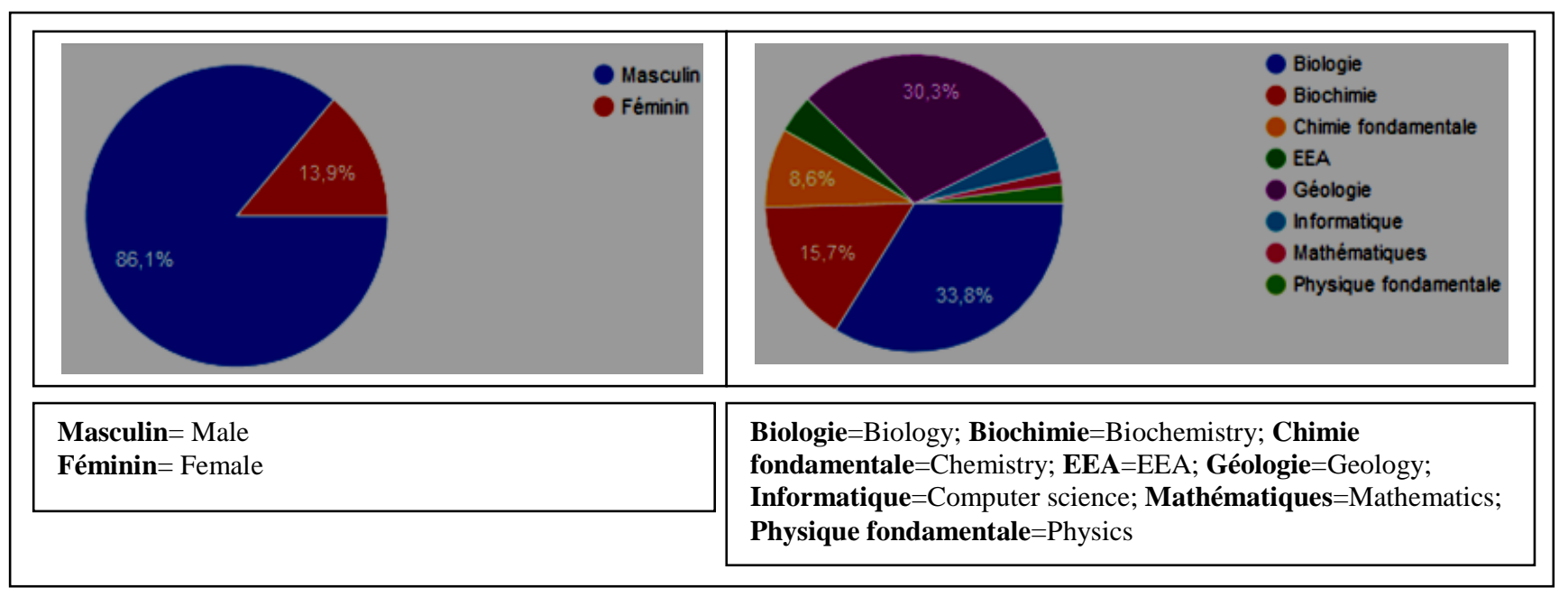

Fig. 2. Learners profil disagreagated by gender and area of specialization.

\section{Website audience}

To date, we have more than 13900 visits $^{13}$ for the project's website. Moreover, since 2016, we are conducting a survey (based on a short website url ${ }^{14}$ ) in order to learn more about the characteristics of the devices used for accessing to our website. The timeframe and the repartition of clicks can be seen in Figure 3.

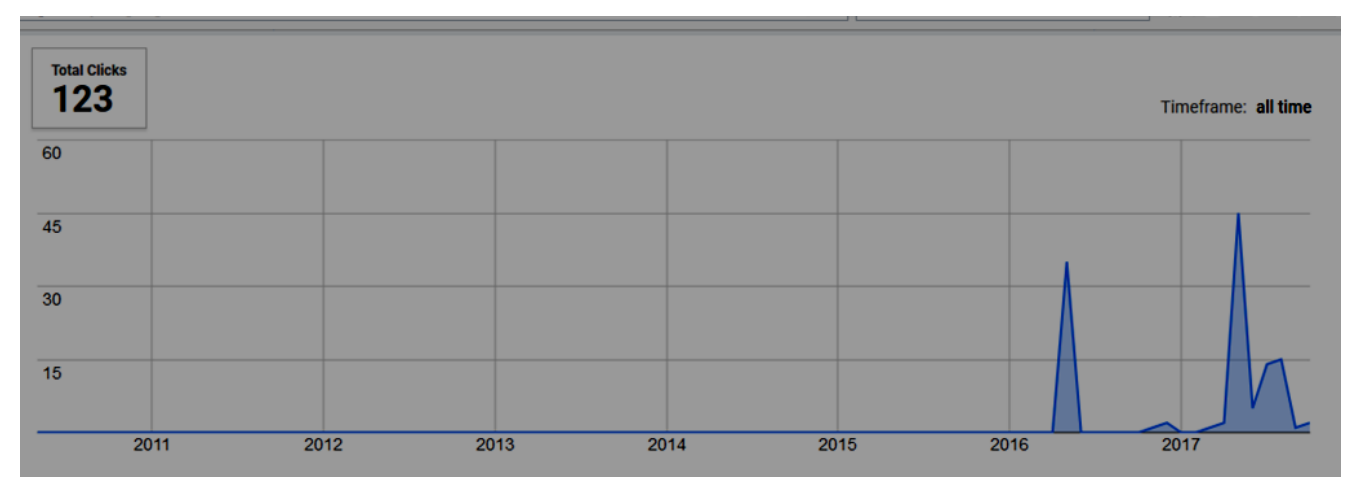

Fig. 3. Timeframe and Total Clicks based on a short website url survey.

13 Accessed on 19/11/2017

${ }^{14}$ https://goo.gl/oFW4C3 


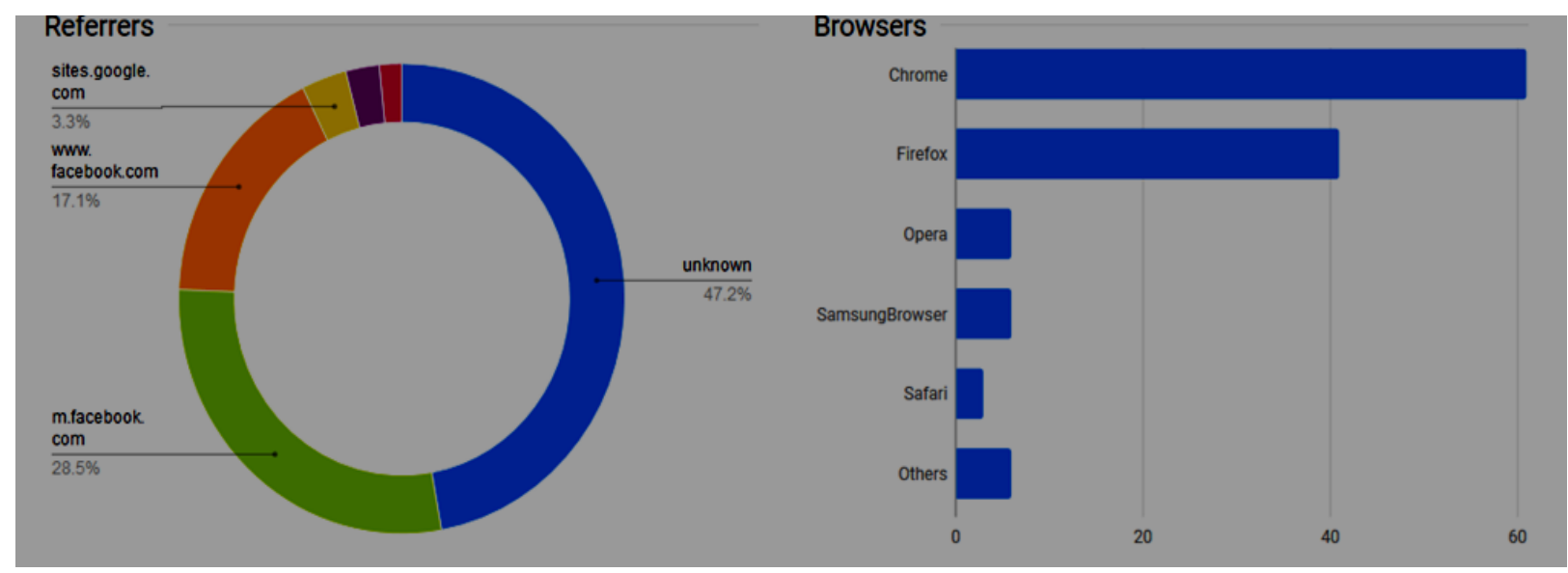

Fig. 4. Referrers and Browsers related to the website audience (survey via short url)..

In Figure 4., the referrers repartition showed that around $47.2 \%$ is unknown, followed by social media, particularly mobile facebook $(28.5 \%)$ and facebook $(17.1 \%)$ users. In terms of browsers, most of the clicks have been performed through Chrome (more than 60 clicks) followed by Firefox (more than 40 clicks). Furthermore, Countries of residence of our website users and their platforms are available in Figure 5.

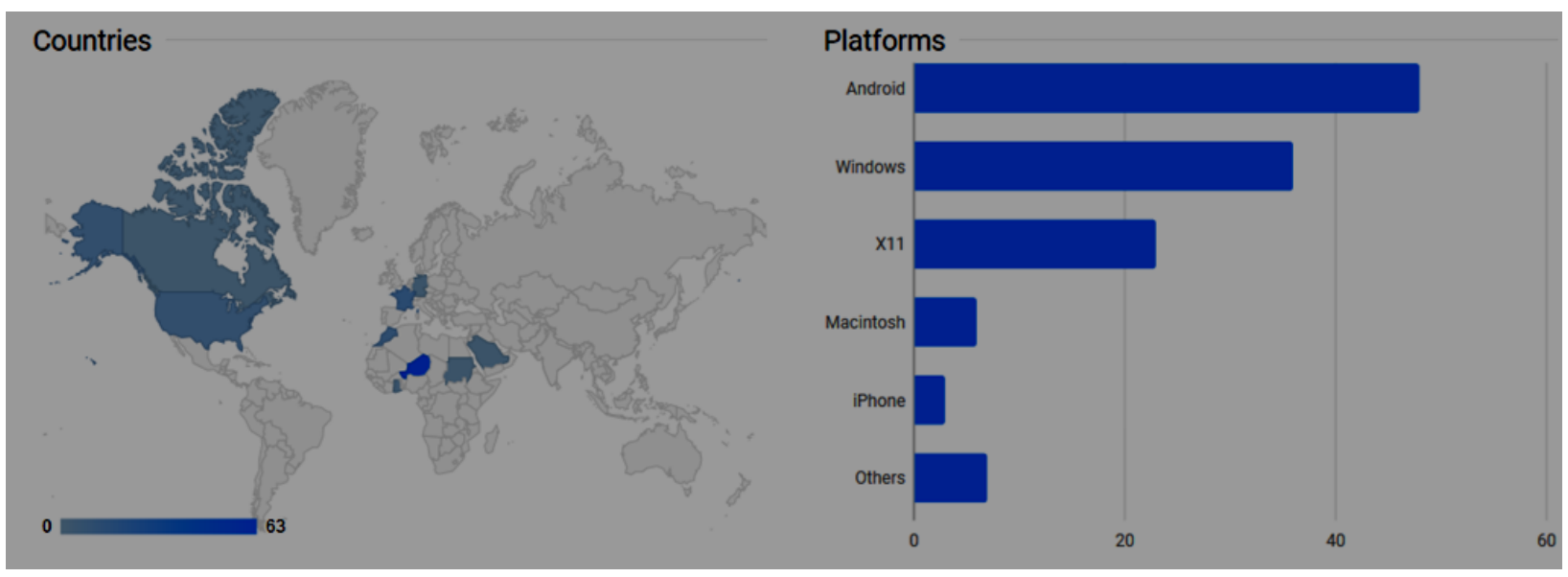

Fig. 5. Countries of residence and Platforms of our website's audience (survey via short url). 


\section{Evaluation and learners perception}

Each year, two modes of evaluation are conducted; online(via project or problem solving approach) and classical one (on paper); in our context it was too difficult to evaluate learners competencies through just online platforms or using only project or problem solving based evaluation due to many reasons (level of adoption of ICT by some students, reliability of the internet and electrical energy supply,...). Perception of students about the integration of $G$ Suite has been also investigated through online forms, discussion forum, learners observation and semi structured interview.

Although students appreciated project or problem solving approach which was related to collaborative mapping (in 2016) and awarness raising about the SDGs ${ }^{15}$, particularly the health impact of indoor air pollution (in 2017); the greatest challenge they faced was when uploading documents or pictures in the collaborative workspace via Google Drive, accessing to the YouTube video or participating to the discussion forum when they are using their mobile devices.

Acknowledgments. The author wish to thank Campus France, Paul Painlevé Laboratory (University of Lille) and CEA-MITIC (Centre d'Excellence Africain en Mathématiques, Informatique et TIC). Their support is greatly appreciated.

\section{Conclusion}

In the knowledge society and a growing number of jobs across all sectors requiring ICT skills, particularly cloud based technology, competency based ICT training is necessary.

Although many developing countries are facing challenges related to the access and use of the internet; teachers and students have to adapt to this changing global environment in order to benefit from the fourth industrial revolution and to meet the demands of the job market .

Our experience through the Google Suite for Education integration revealed us that young students have the ability to be greater innovators if they can find an enabling environment and ressources.

Communication tools (Gmail, Google Hangouts) allowed connection with email, chat, and video conference. Collaboration tools (Docs, Sheets, Presentation, Drive) allowed real time co-editing documents, spreadsheets, and presentations. In terms of tasks management, tools like Google Keep and Calendar, helped us in building to-do lists, creating task reminders, and scheduling meetings and projects. In terms of classroom management, tools like Google Classroom and Forms helped us in creating classes, distributing assignments, giving quizzes gathering and sending feedback.

From 2015 to 2017, around 400 students on average participated to the project each year including $86 \%$ of Male and $14 \%$ of female. Moreover, the project website seemed to be visited through mobile devices running on Android platform.

As perspectives, it is important to see how the gender inequality in terms of access to ICT can be reduced and how the project can be extended to other faculties and national universities so that it could contribute in achieving the Sustainable Development Goals. Finally, the project

\footnotetext{
${ }^{15}$ Sustainable Development Goals
} 
YouTube channel is a step forward for developing Massive Open Online Courses (MOOCs) in a near future.

\section{References}

[1] Université Abdou Moumouni: Plan Stratégique 2017-2021, Niamey, Niger (2017)

[2] Université Abdou Moumouni: Bilan 2011-2017, Niamey, Niger) (2017)

[3] Université Abdou Moumouni: Termes de références des premieres journées scientifiques nationales (2013)

[4] UNESCO: ICT Competency Framework for Teachers. Paris, UNESCO (2011)

[5] Heo, H., Lim, K. Y., Seo, J. and Kim, Y. : Competency Modelling for 21st Century Learners and Teachers. KR 2011-2. Seoul, Korea Education and Research Information Service (KERIS), (2011)

[6] UNESCO (United Nations Educational, Scientific and Cultural Organisation) : Competency Standards Modules. ICT Competency Standards for Teachers. Paris, UNESCO (2008)

[7] Karsenti, T., Collin, S. et Harper-Merrett, T: Intégration pédagogique des TIC: Succès et défis de 100+ écoles africaines. Ottawa, ON: IDRC (2012)

[8] United Nations Economic and Social Concil: Report of the Inter-Agency and Expert Group on Sustainable Development Goal Indicators (2016)

[9] United Nations factsheets: Youth and ICT (2012)

[10] Ericsson and the Earth Institute at Columbia University: ICT and SDGs, Final report (2016)

[11] OECD (The Organisation for Economic Co-operation and Development) : Education at a Glance: OECD Indicators (2014)

[12] Shear, L., Gallagher, L., and Patel, D: Innovative Teaching and Learning Research: 2011 Findings and Implications. SRI International and Microsoft Partners in Learning (2011)

[13] Karsenti, T., Collin, S. \& Dumouchel, G : L'usage intensif des technologies en classe favorise-t-elle la réussite scolaire ? Dans B. Wentzel \& S. Boechat-Heer (dir.), Génération connectée (p. 71-89). Berne: Peter Lang. (2012)

[14] Karsenti, T., Villeneuve, S., Raby, C., Weiss Lambrou, R. \& Meunier, H. : Conditions d'efficacité de l'intégration des TIC en pédagogie universitaire pour favoriser la persévérance et la réussite aux études (Rapport de recherche du Centre de recherche interuniversitaire sur la formation et la profession enseignante). Montréal, QC : CRIFPE, Université de Montréal (2007).

[15] Reeger, B. and Bunders, J.: Knowledge co-creation: Interaction between science and society, Preliminary studies and background studies, number V.10e, Den Haag, The Netherlands (2009). 